\title{
Grain Refinement During Directionally Solidifying GCr18Mo Steel at Low Pulling Speeds Under an Axial Static Magnetic Field
}

\author{
Yuan Hou ${ }^{1} \cdot$ Zhen-Qiang Zhang $^{1} \cdot$ Wei-Dong Xuan ${ }^{1} \cdot$ Jiang Wang $^{1} \cdot$ Jian-Bo $\mathrm{Yu}^{1} \cdot$ Zhong-Ming Ren $^{1}$
}

Received: 3 August 2017 / Revised: 31 August 2017 / Published online: 15 December 2017

(C) The Chinese Society for Metals and Springer-Verlag GmbH Germany, part of Springer Nature 2017

\begin{abstract}
The present work investigates how axial static magnetic field affects the solidification structure and the solute distribution in directionally solidified GCr18Mo steel. Experimental results show that grain refinement and the columnar to equiaxed transition is enhanced with the increases in the magnetic field intensity $(B)$ and temperature gradient $(G)$ and the decrease in the growth speed. This phenomenon is simultaneously accompanied by more uniformly distributed alloying elements. The corresponding numerical simulations verify a thermoelectric (TE) magnetic convection pattern in the mushy zone due to the interaction between the magnetic field and TE current. The TE magnetic convection in the liquid should be responsible for the motion of dendrite fragments. The TE magnetic force acting on the dendrite is one of the driving forces trigging fragmentation.
\end{abstract}

Keywords GCr18Mo steel · Grain refinement - Axial static magnetic field · Columnar to equiaxed transition · Thermoelectric magnetic force

\section{Introduction}

Steels with a fine-grain structure, associated with excellent mechanical properties, are the ultimate goal of the entire manufacturing process, especially in the solidification process [1-4]. It plays a significant role in the hot-soak and hot rolling of the steel [5]. Compared with chemical methods [6-8], several environment-friendly physical approaches have been applied into grain refinement during the solidification stage, such as ultrasonic vibration and mechanical or electromagnetic stirring [9-11]. The application of electromagnetic fields for stirring the molten metal is particularly attractive due to the completely contactless feature and flexible tailoring of the magnetic fields themselves. These time-varying magnetic fields mainly

Available online at http://link.springer.com/journal/40195

Jiang Wang

jiangwang@i.shu.edu.cn

$\triangle$ Zhong-Ming Ren

renzm2201@163.com

1 State Key Laboratory of Advanced Special Steel and School of Materials Science and Engineering, Shanghai University, Shanghai 200072, China include induction coils in furnaces [12], pulsed magnetic fields [13] and rotating or travelling magnetic fields $[14,15]$. Manifold investigations have declared that an apparent decrease in grain size can be achieved with increasing intensity of forced convection generated by applying the time-varying magnetic fields in the solidifying melt [16-20].

In contrast to the time-varying magnetic fields, static magnetic fields are applied to suppress the flow in a solidifying, electrically conducting melt because of the braking effect of the Lorentz force [21]. The Latter is caused by interaction between electric current, induced by a moving melt and the imposed magnetic field. Even so, during solidification the thermo-physical properties of bulk materials subjected to temperature gradients can change abruptly owing to phase transition. This gives rise to appearance of a TE current near the liquid/solid interface and further to the TE magnetic force resulted from interaction between the TE current and the applied magnetic field. The TE magnetic force affects the solidification processes ranging from a form of convection, transport of the solid phase in the liquid to strain and deformation of the solidified structure [22-25]. Notably, the TE magnetic force imposed on dendrites and equiaxed grains breaks the columnar dendrite and drives the motion of dendrite 
fragmentation and equiaxed grains in the mushy zone [26]. It is commonly known that grain refinement in the absence of inoculants is generated by fragmentation of dendritic structures existing in the mushy zone [27-29]. Identical conclusions were obtained in the directional solidification of Al-base alloys, $\mathrm{Pb}-\mathrm{Sn}$ alloys and $\mathrm{Ni}$ base superalloys where the CET occurred at low pulling speeds [26, 30-32]. Although the CET has been observed in the directionally solidified alloys mentioned above, there are relatively few studies devoted to study the CET and grain refinement in the steel at low pulling speeds with an axial static magnetic field.

In the solidification process of the steel, the temperature gradient causes dendritic growth to take on a columnar structure and ultimately results in the formation of the elongated dendrite zone of the ingot. Directional solidification enables independent control of both the pulling speed and the temperature gradient over a given range to study the columnar dendritical evolution during solidification. A Bridgman-Stockbarger-type furnace fixed in a

Table 1 Chemical compositions of GCr18Mo steel (wt\%)

\begin{tabular}{llllllll}
\hline $\mathrm{C}$ & $\mathrm{Cr}$ & $\mathrm{Mo}$ & $\mathrm{Si}$ & $\mathrm{Mn}$ & $\mathrm{P}$ & $\mathrm{S}$ & $\mathrm{Fe}$ \\
\hline 0.96 & 1.65 & 0.2 & 0.39 & 0.31 & 0.0027 & 0.0021 & Bal.
\end{tabular}

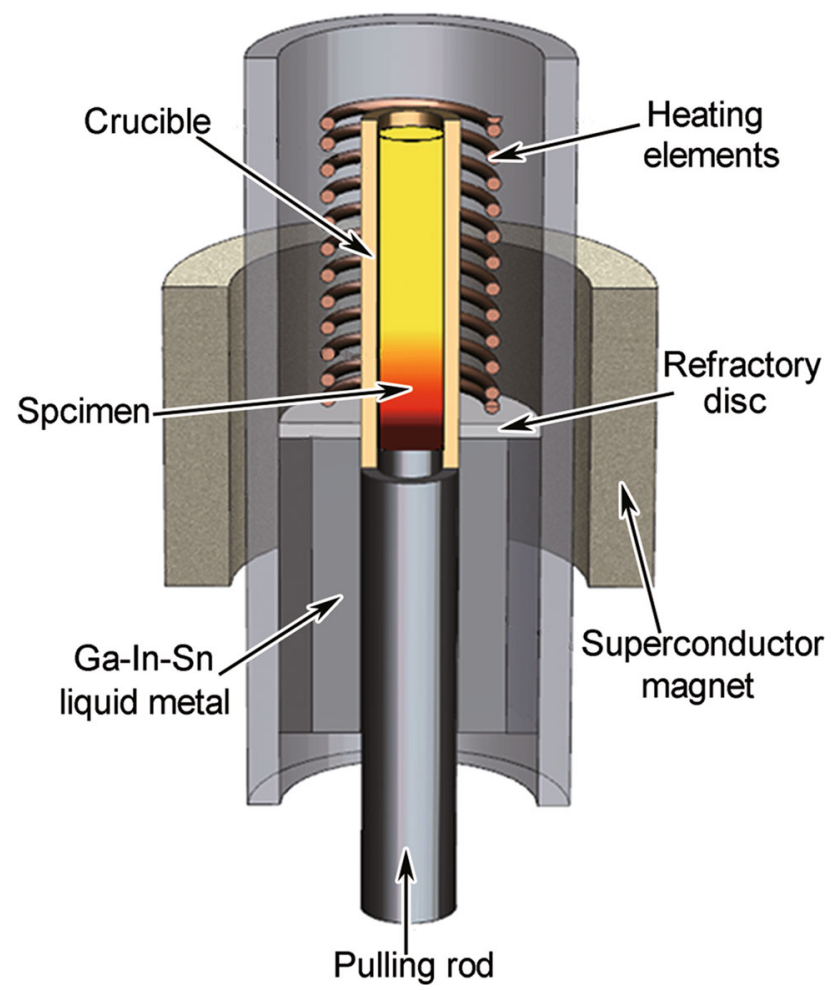

Fig. 1 Schematic illustration of Bridgman solidification apparatus in superconductor magnet static superconducting magnet can create a thermal gradient along the direction of solidification and easily control the growth speed of alloys. It can satisfy both the work conditions of the TE magnetic force and columnar grains. Using this idea as basis, we investigate the effect of the axial static magnetic field on grain refinement of GCr18Mo steel.
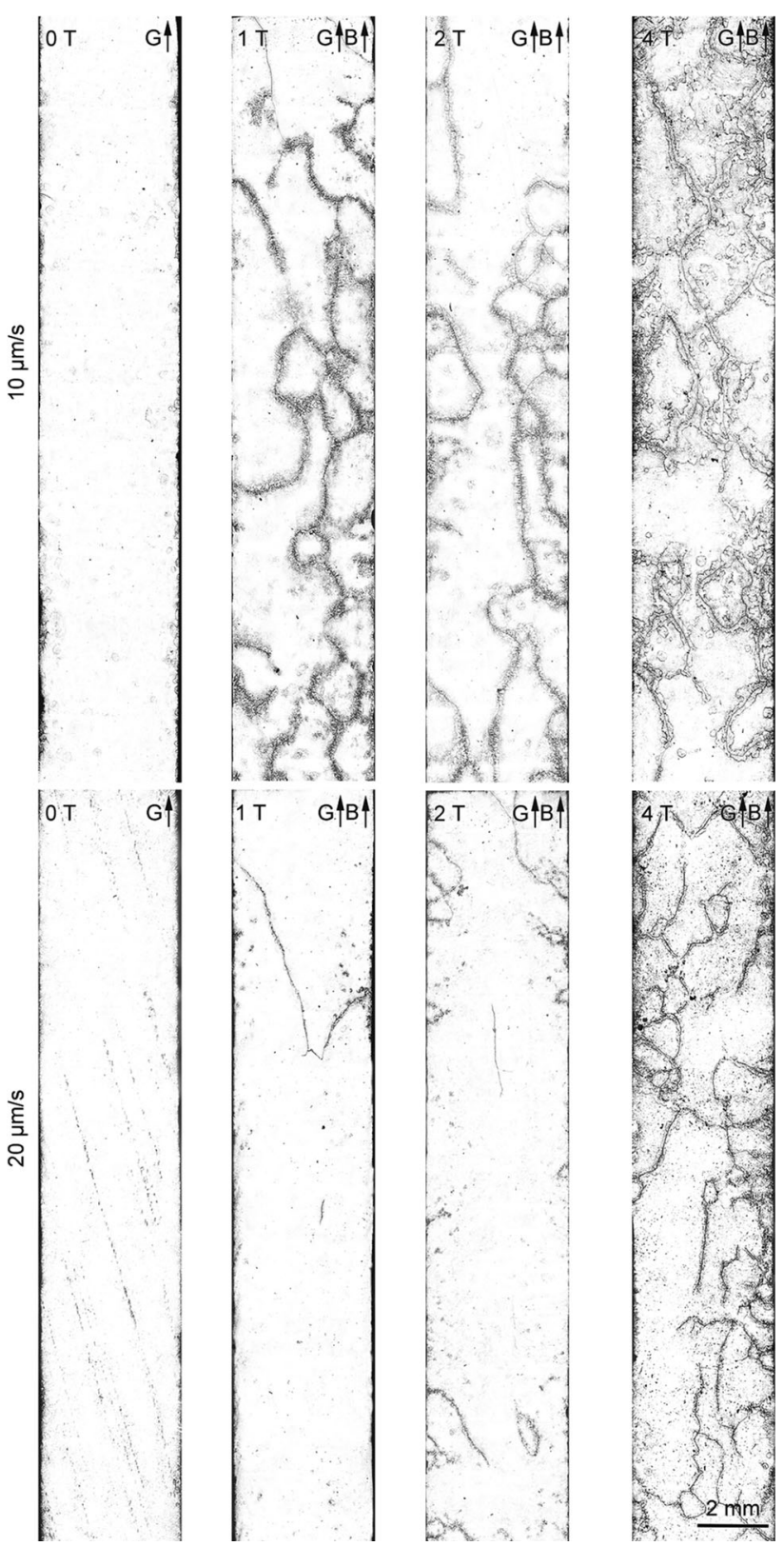

Fig. 2 Longitudinal solidification structures of GCr18Mo steel specimen at various magnetic field intensities and growth speeds under temperature gradient of $104 \mathrm{~K} / \mathrm{cm}$ 


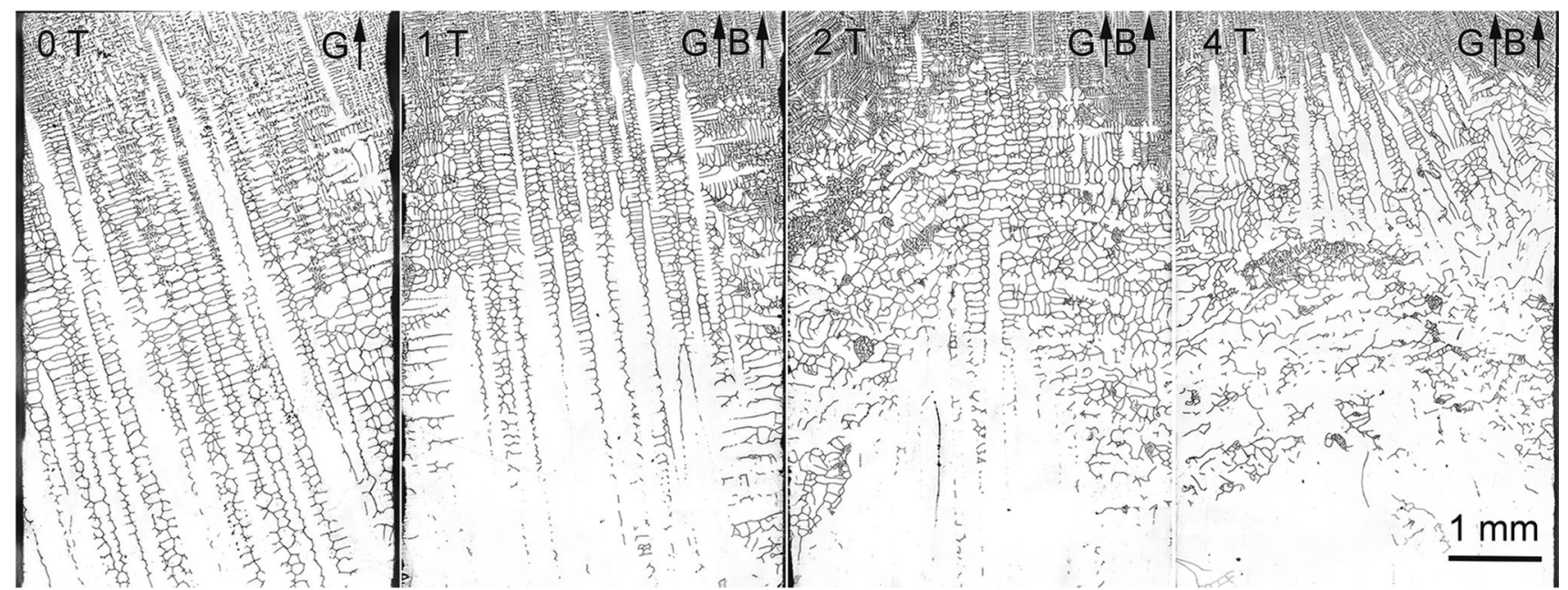

Fig. 3 Longitudinal microstructures near liquid/solid interfaces of GCr18Mo steel specimen at growth speed of $20 \mu \mathrm{m} / \mathrm{s}$ and various axial static magnetic field intensities under temperature gradient of $104 \mathrm{~K} / \mathrm{cm}$

\section{Experimental}

The compositions of GCr18Mo steel are listed in Table 1. The samples with $4 \mathrm{~mm}$ in diameter and $180 \mathrm{~mm}$ in length for the directional solidification were electro-discharge machined from the steel ingots with a diameter of $100 \mathrm{~mm}$. These samples subsequently enveloped in high-purity corundum tubes with the inner diameter of $4 \mathrm{~mm}$ and length of $200 \mathrm{~mm}$, respectively. The apparatus, as shown in Fig. 1, mainly consists of a static superconductor magnet, a Bridgman-Stockbarger-type furnace and a growth velocity and temperature controller. The superconducting magnet can generate an axial static magnetic field with the adjustable intensity up to $8 \mathrm{~T}$. There is a uniform magnetic field space with the diameter of $300 \mathrm{~mm}$ and length of $80 \mathrm{~mm}$ in the centre of this magnet. The furnace made of nonmagnetic material has a negligible effect on the uniformity of magnetic field. The temperature gradient was established between the heating zone and the cooling zone. The temperature of the heating zone with an argon atmosphere can reach $1600 \pm 1{ }^{\circ} \mathrm{C}$ by means of a consistently heated graphite tube. The cooling zone containing liquid Ga-In-Sn metal at room temperature is used for quenching. For the directional solidification experiments, the sample was moved downward at a defined velocity while the furnace was fixed. The sample was put into the centre of the magnet during the experiment. It was ensured that the liquid/solid interface of the sample was placed on the uniform magnetic field. The specimens in a corundum crucible were melted and directionally solidified in the furnace by pulling the crucible assembly at various speeds into the cooling zone. To identify the morphology of the liquid-solid interface of samples during the crystallization course, quenching experiments were performed after $60 \mathrm{~mm}$ steady-state growth of the specimens.

The morphology of the solidification microstructures was observed by optical microscopy (DM 6000M, Leica, Germany). The samples were cut-across the longitudinal section, polished and etched in saturated solution of picric acid at $80{ }^{\circ} \mathrm{C}$. The distribution of the solute chromium in the solid near the solid/liquid interface was detected in a high-resolution scanning electron microscope (FEG quanta 450) equipped with energy-dispersive spectroscopy (EDS). Chromium alone was determined, because other elements were either too light or too low in content to be detected [33].

\section{Experimental Results}

Figure 2 shows that solidification structures of GCr18Mo steel specimen at various axial static magnetic field and growth speeds under the $104 \mathrm{~K} / \mathrm{cm}$ temperature gradient. The corresponding longitudinal solidification microstructures near the liquid/solid interface are shown in Fig. 3. Larger columnar grains are produced along the longitudinal section of the specimens without axial static magnetic field application. With increasing intensity of the axial static magnetic field, columnar grains gradually become equiaxed grains at the growth speed of 10 and $20 \mu \mathrm{m} / \mathrm{s}$. However, the axial static magnetic field is tended to promote the grain refinement at lower growth rate. From the corresponding longitudinal microstructures near the liquid/solid interface, it can be seen that the dendrite morphology without the axial static magnetic field is typical columnar. When the axial static magnetic field is applied, 


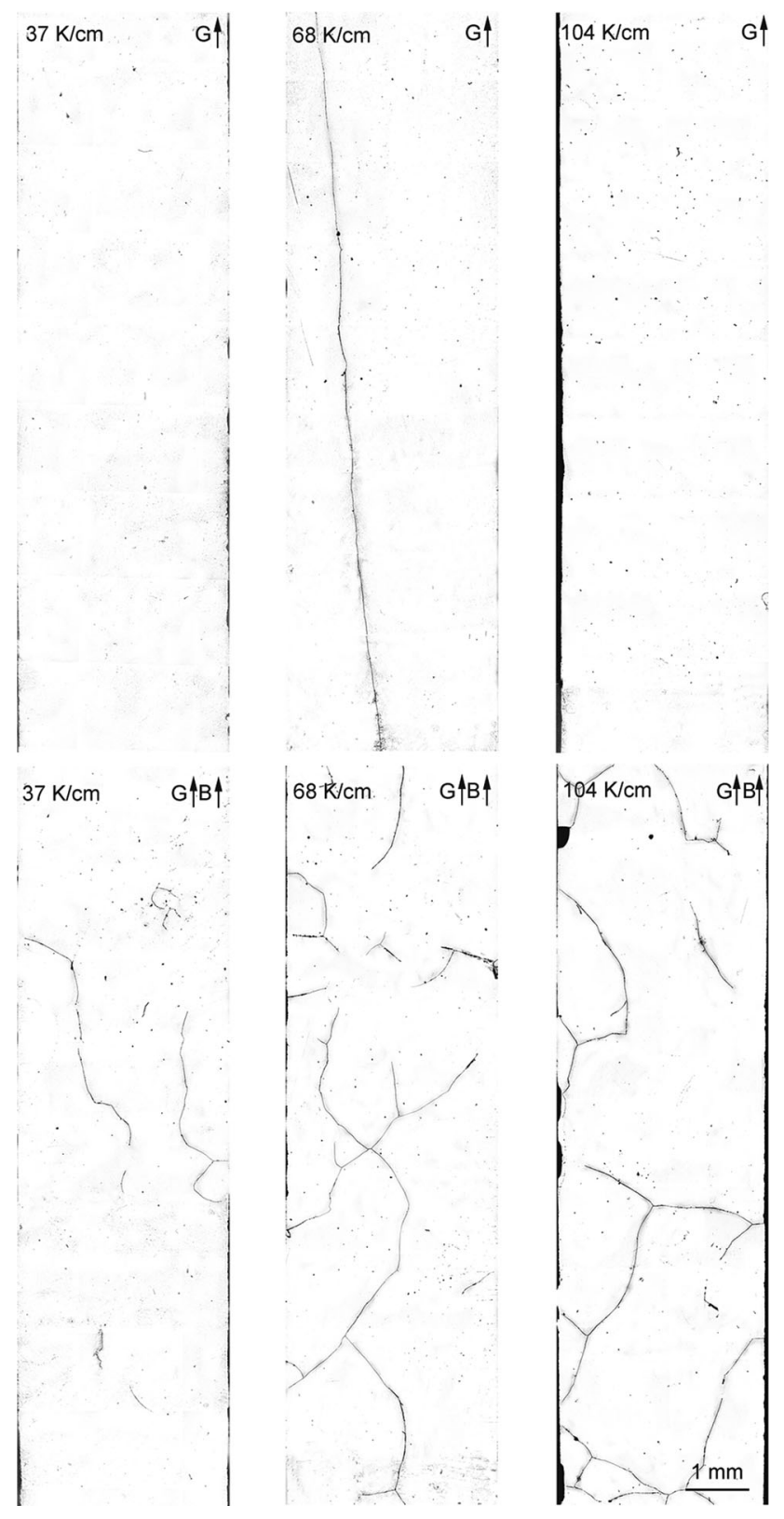

Fig. 4 Longitudinal solidification structures of GCr18Mo steel specimen at growth speed of $5 \mu \mathrm{m} / \mathrm{s}$ and various temperature gradients without and with $4 \mathrm{~T}$ axial static magnetic field

regular columnar dendrites are destroyed and tend to transform into equiaxed dendrites.

The solidification structures of GCr18Mo steel specimen at the growth speed of $5 \mu \mathrm{m} / \mathrm{s}$ under various temperature gradients are exhibited in Fig. 4. Larger columnar grains are generated along the longitudinal section of the specimens in the absence of a magnetic field. With increasing the temperature gradient, columnar grains become equiaxed grains at the growth speed of $5 \mu \mathrm{m} / \mathrm{s}$ under the 4 $\mathrm{T}$ axial static magnetic field. In addition, the dendrites are all regular at various temperature gradients without axial static magnetic field from the corresponding microstructures near the liquid/solid interface as displayed in Fig. 5. Columnar dendrites degenerate and transform into equiaxed dendrites as the temperature gradient increases with the $4 \mathrm{~T}$ axial static magnetic field.

Figure 6 presents the radial distribution of the $\mathrm{Cr}$ content in the solid at the position of $20 \mathrm{~mm}$ from the solid/ liquid interface fabricated in the same condition. It can be indicated that the fluctuation range of the $\mathrm{Cr}$ content decreases as the axial static magnetic field intensity increases. In Fig. 2, as the axial static magnetic field intensity increases, the size of the grain decreases. It means that grain refinement induced by the axial static magnetic field can improve the composition homogenization of GCr18Mo steel.

\section{Computation Description and Results}

The numerical simulations just emphasize the effect of the external magnetic field on the fluid flow without considering the heat transfer or the solidification process. To calculate the thermoelectric currents at the solid/liquid interface during directional solidification, a complementary term is added to Ohm's law:

$J=-\sigma(\nabla V+S \nabla T)$

where $J, \sigma, V, S$ and $\nabla T$ are the thermoelectric current density, the electrical conductivity, the electric scalar potential, the absolute thermoelectric power and temperature gradient, respectively. The second item in the bracket on the right-hand side of this equation is the contribution of the thermoelectric current. The thermoelectric current density satisfies the continuity equation:

$\nabla \cdot J=0$

Both Eqs. (1) and (2) are valid in the liquid and solid. Another complementary term, $\boldsymbol{\mu} \times \boldsymbol{B}$ ( $\boldsymbol{\mu}$ is the fluid velocity field and $\boldsymbol{B}$ is the applied axial static magnetic field), will be added to Eq. (2) in the presence of magnetic fields. Equations (1) and (2) are solved in terms of the electric scalar potential $V$ in the liquid and solid. More details regarding the equations and corresponding boundary conditions are described in Ref. [34]. With a fixed and given solid/liquid interface, a commercial finite element code COMSOL multiphysics is applied to solve this system in the liquid and solid phases simultaneously. A prescribed interface, as a heuristic model, qualitatively explains how the TE current and TE magnetic convection are created. The physical properties of GCr18Mo steel used in the numerical simulation are given in Table 2 [35-37]. Figures $7,8,9$ display the numerical simulation for the TE magnetic effects in directionally solidified GCr18Mo steel 

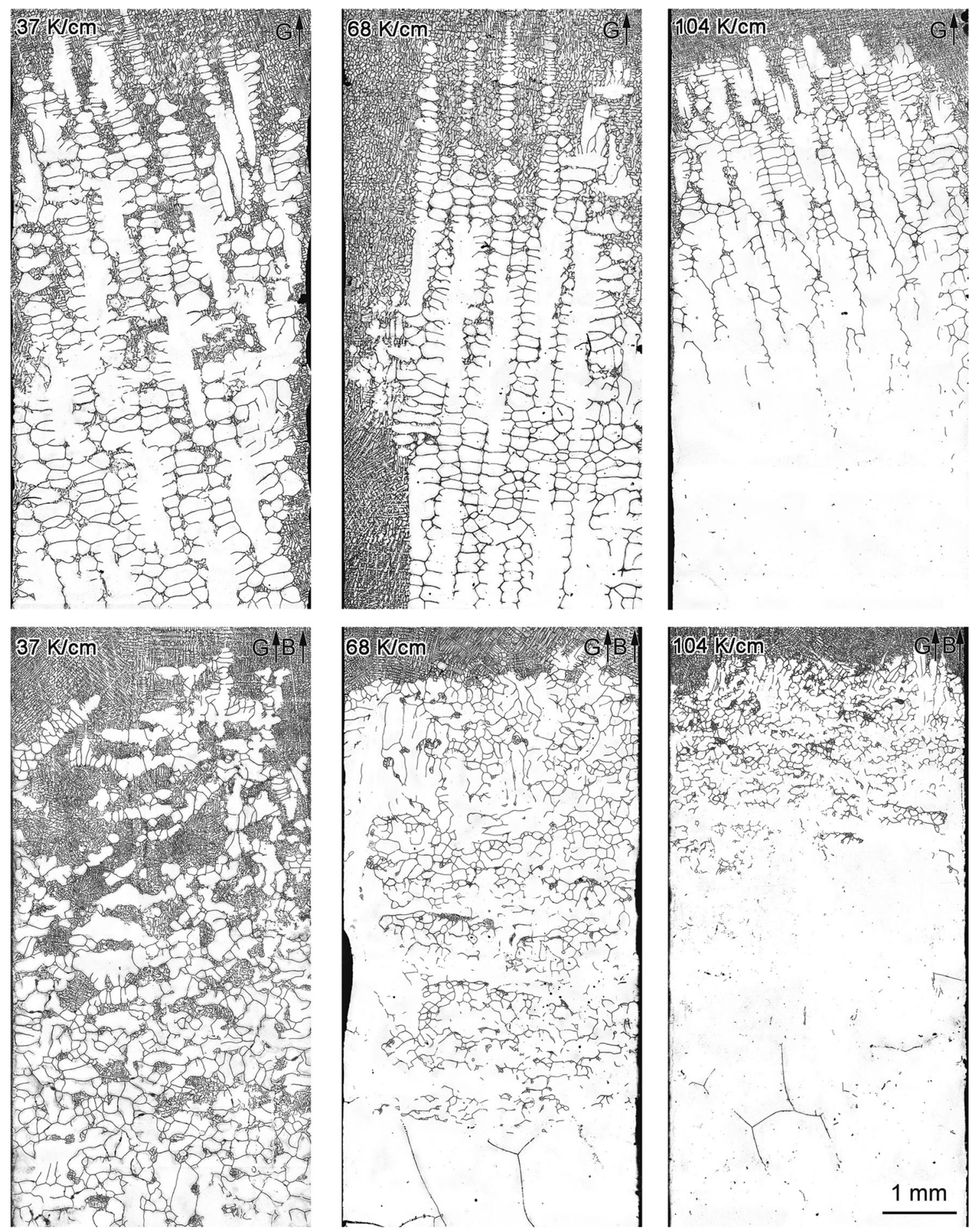

Fig. 5 Longitudinal microstructures near liquid/solid interfaces of GCr18Mo steel specimen at growth speed of $5 \mu \mathrm{m} / \mathrm{s}$ and various temperature gradients without and with $4 \mathrm{~T}$ axial static magnetic field

under an axial static magnetic field. The geometry of the computation domain of the solid/liquid interfaces is shown in Fig. 7a. Figure 7b exhibits the corresponding typical computed TE currents in the liquid near the solid/liquid interface. It should be pointed out that the maximum density of the TE current appears in the mushy region. Figure $7 \mathrm{c}$ shows the general 3D view of the computed TE magnetic convection under an axial static magnetic field of $2 \mathrm{~T}$ and a temperature gradient of $104 \mathrm{~K} / \mathrm{cm}$. To gain more insight, the corresponding $2 \mathrm{D}$ views seen from the positive 


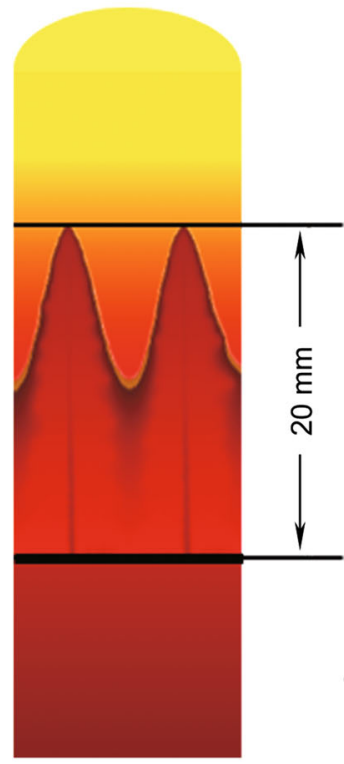

Radial direction
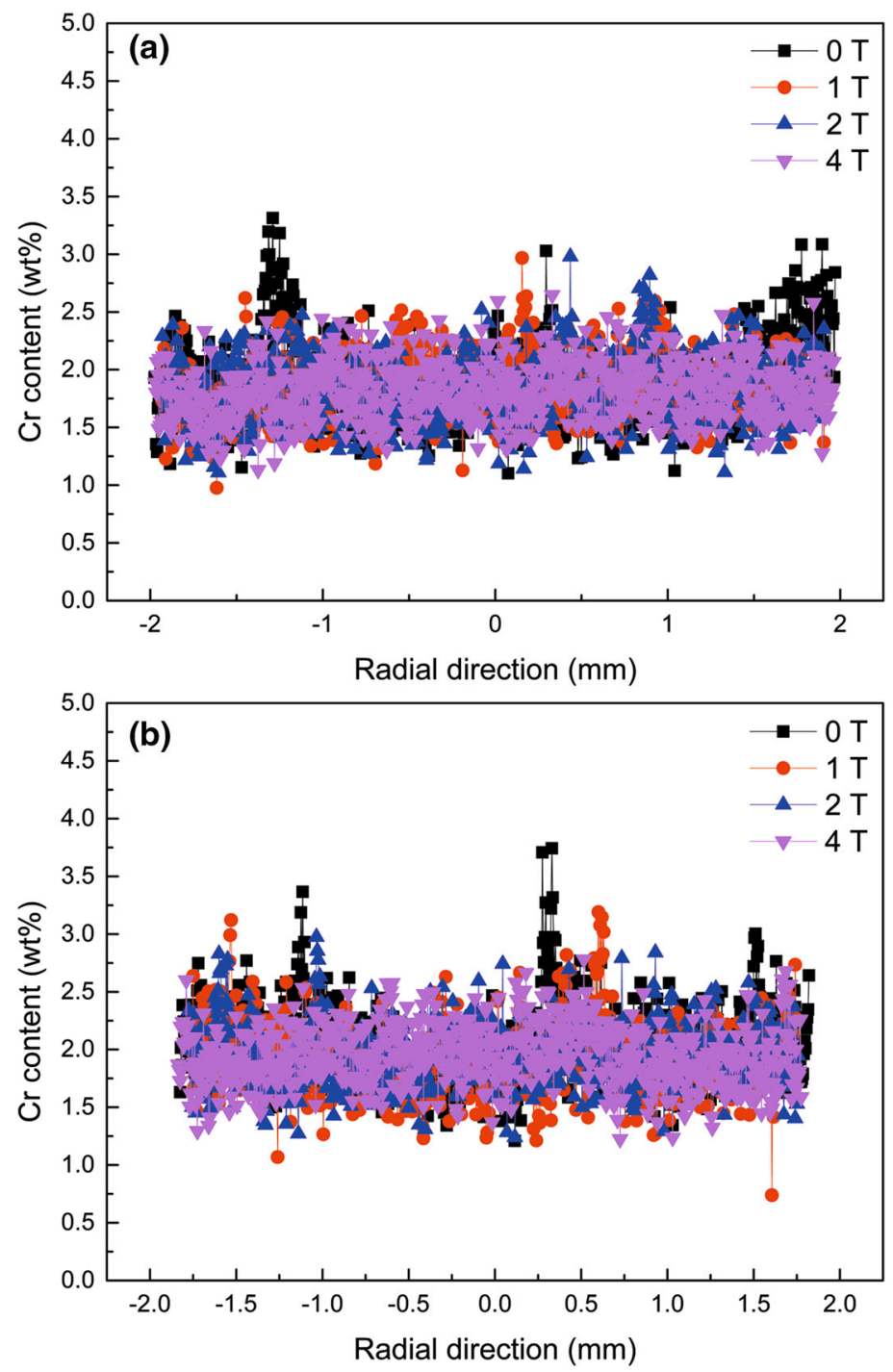

Fig. $6 \mathrm{Cr}$ contents for radial profiles in solid at $20 \mathrm{~mm}$ from the solid/liquid interface (indicated by the graph on the left) fabricated under temperature gradient of $104 \mathrm{~K} / \mathrm{cm}$ with growth speeds of $10 \mu \mathrm{m} / \mathrm{s} \mathrm{a}, 20 \mu \mathrm{m} / \mathrm{s} \mathrm{b}$

Table 2 Physical properties and parameters in numerical simulation

\begin{tabular}{llll}
\hline Name and symbol & Unit & Solid & Liquid \\
\hline Absolute thermoelectric power $(S)$ & $\mathrm{V} / \mathrm{K}$ & $-1 \times 10^{-6}$ & $-4 \times 10^{-6}$ \\
Dynamic viscosity $(\mu)$ & $\mathrm{Pa} \mathrm{s}$ & - & $5.5 \times 10^{-3}$ \\
Electrical conductivity $(\sigma)$ & $(\Omega \mathrm{m})^{-1}$ & $8.5 \times 10^{5}$ & $7.2 \times 10^{5}$ \\
Density $(\rho)$ & $\mathrm{Kg} / \mathrm{m}^{3}$ & $7.4 \times 10^{3}$ & $7.02 \times 10^{3}$ \\
Thermal conductivity $(\lambda)$ & $\mathrm{W} /(\mathrm{mK})$ & 32.5 & 31.2 \\
\hline
\end{tabular}

$z$-axis at various positions are given in Fig. $7 \mathrm{~d}$. It is worthwhile mentioning that the TE magnetic convection is a typical circumfluence in the mushy zone. The distribution of the TE magnetic convection in the $x-z$ plane under the $104 \mathrm{~K} / \mathrm{cm}$ temperature gradient is illustrated in Fig. 8. It suggests that the TE magnetic convection mainly generates in the mushy zone. The maximum value of the convection intensity at the edge of the samples decreases with increasing magnetic field intensity while the one in the centre changes slightly. This result is consistent with the observation of our previous studies [23, 38]. Moreover, Fig. 9 plots the distribution of the computed TE magnetic convection at various temperature gradients under the $4 \mathrm{~T}$ axial static magnetic field. Notably, the convection intensity increases as the temperature gradient increases under the $4 \mathrm{~T}$ axial static magnetic field. 


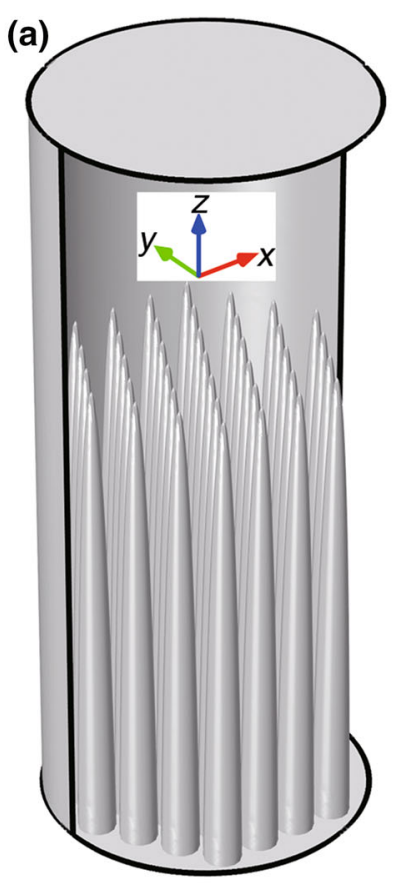

(b)

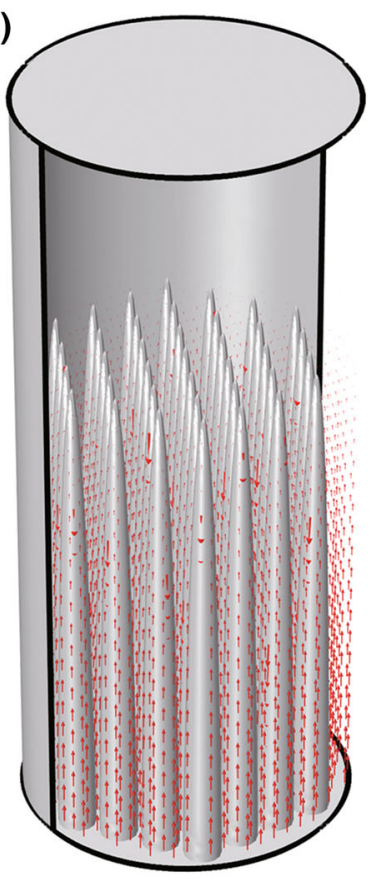

(c1)

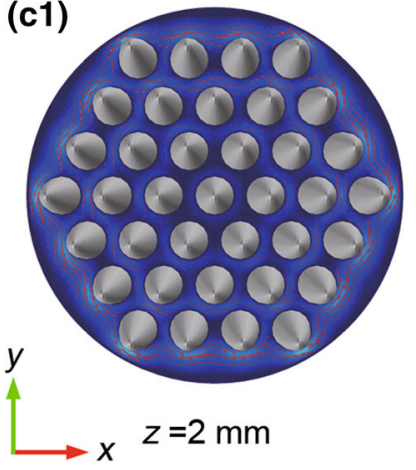

(c2) (c)
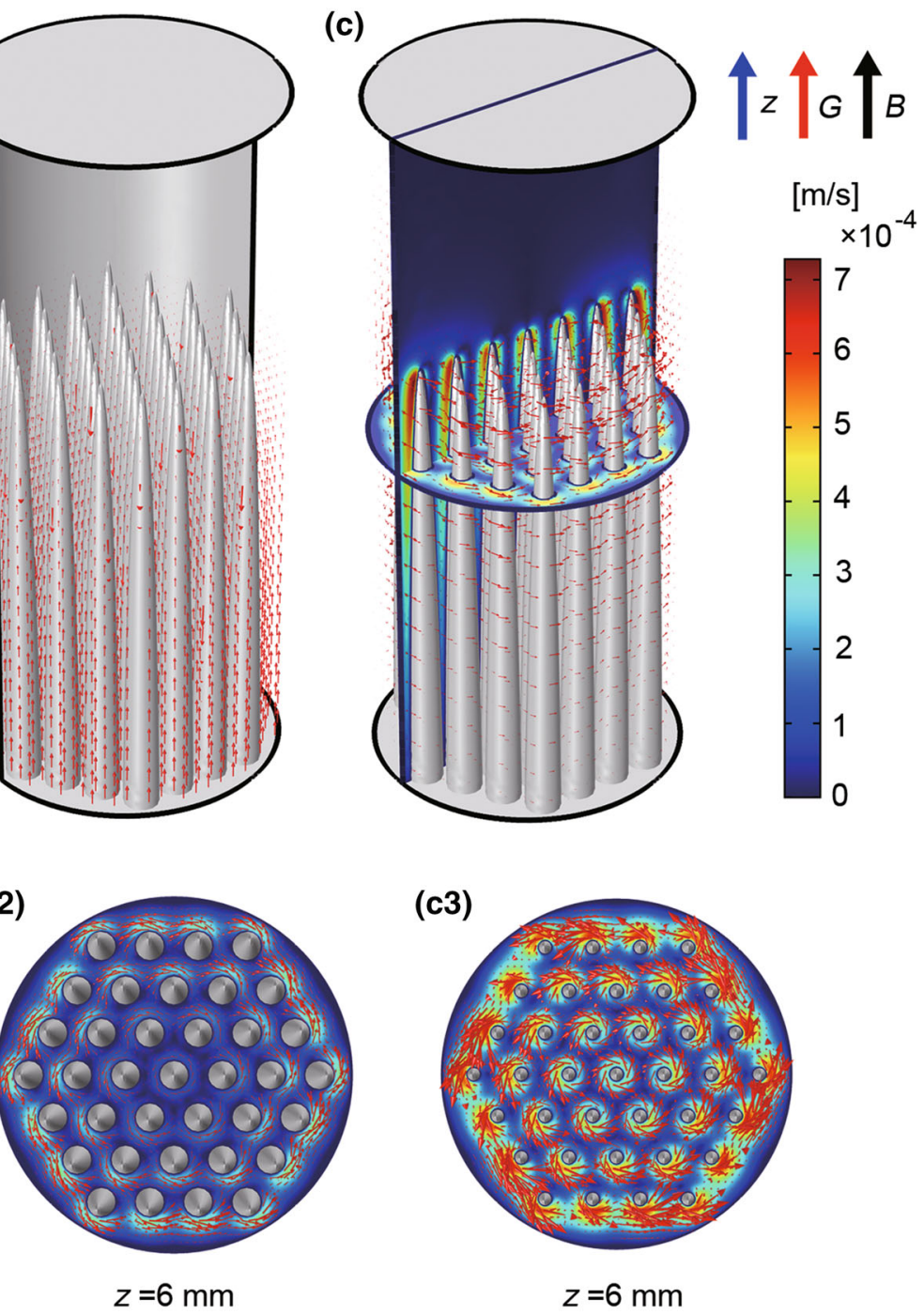

(c3)

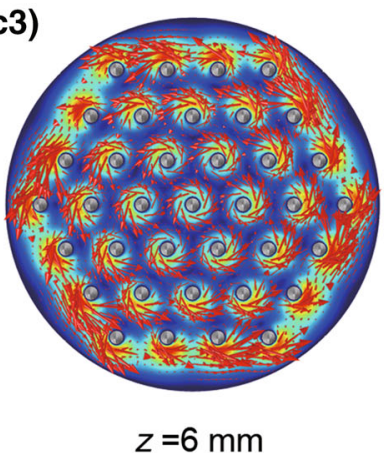

Fig. 7 Numerical simulation for TE magnetic effects in directionally solidified GCr18Mo steel under a 2 T axial static magnetic field: a geometry of computation domain; b computed TE current; c computed TE magnetic convection (c1, c2 and $\mathbf{c 3}$ show the direction and magnitudes of computed TE magnetic convection in $x-y$ plane at different positions in mushy zone)

\section{Discussion}

There is no denying that grain refinement in the absence of inocculants results from fragmentation of dendritic structures existing in the mushy zone. On the one hand, the fragments in various alloys may be produced by several mechanisms such as ripening or recalescence, or via solute remelting of the necks of individual dendrite arms. The mechanical deformation from various sources (gravity, buoyancy, liquid flow and external deformation) combined with transgranular liquation cracking mechanisms may be essential for grain fragmentation during solidification [39]. In our previous work [26], the value of the TE magnetic force imposed on the dendrite as a function of the magnetic field intensity $(B)$ and temperature gradient $(G)$ was studied and can be written as:

$$
F_{T E}=\frac{\sigma_{l} \sigma_{s} f_{l}}{\sigma_{l} f_{l}+\sigma_{s} f_{s}}\left(S_{s}-S_{l}\right) G B
$$

where $\sigma, f$ and $S$ are the electrical conductivity, phase fraction and thermoelectric power, respectively. The subscripts $s$ and $l$ are the solid and liquid phases, respectively. The value of the TE magnetic force increases as the magnetic field intensity and the temperature gradient increase. In this work, for GCr18Mo steel, the magnitude of the TE magnetic force under the $4 \mathrm{~T}$ magnetic field is of order of $10^{5} \mathrm{~N} / \mathrm{m}^{3}$. The stress is induced by the TE magnetic force, localized into the root of the dendrite, as another driving force for causing the dendrite to fragment (Fig. 10).

On the other hand, numerous investigations have pointed out that a pronounced decrease in grain size can be 

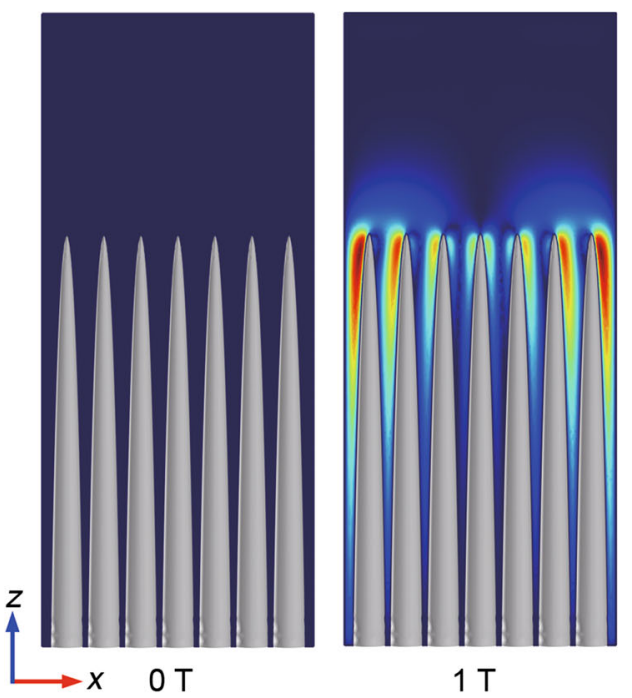

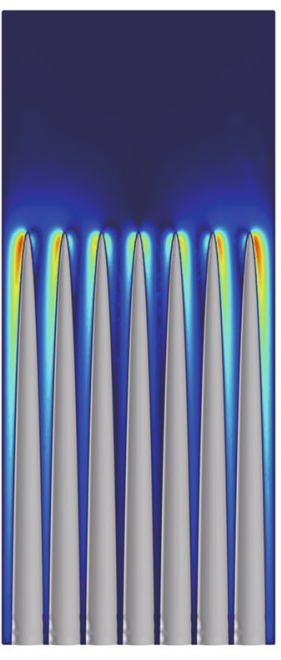

$2 \mathrm{~T}$
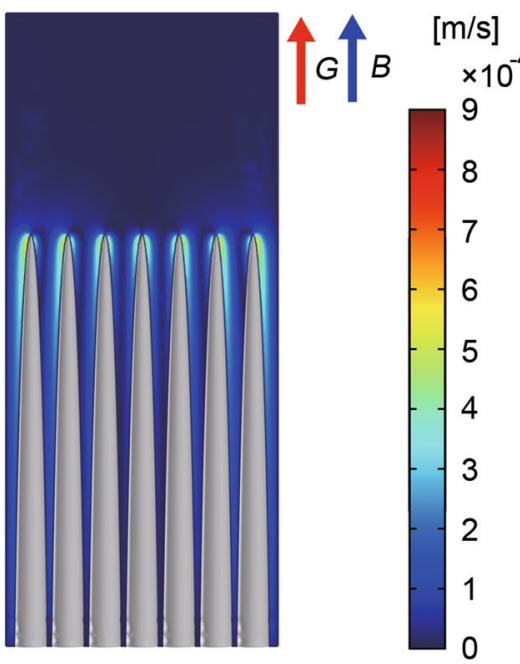

$4 \mathrm{~T}$

Fig. 8 Distribution of computed TE magnetic convection during directional solidification of GCr18Mo steel at various axial static magnetic field intensities under temperature gradient of $104 \mathrm{~K} / \mathrm{cm}$
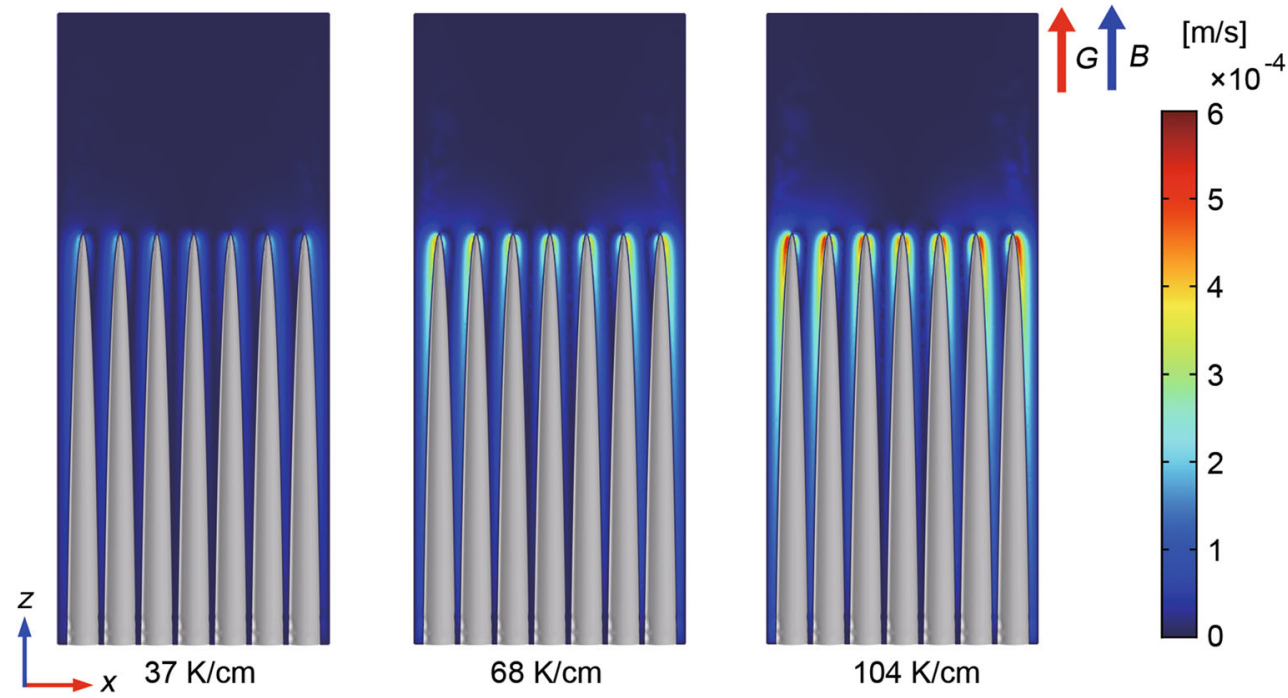

Fig. 9 Distribution of computed TE magnetic convection at various temperature gradients during directional solidification of GCr18Mo steel under $4 \mathrm{~T}$ axial static magnetic field

obtained with increasing intensity of forced convection in the solidifying melt $[27,28]$. Hellawell et al. [40] suggest that the flow transports the fragments from the interdendritic spacing to the region ahead of the solidification front. According to Hunt model [41], the advancing columnar solidification front stops as soon as the concentration of the equiaxed grains has reached a critical value. In the present work, from the numerical and estimation results, potential fragments of GCr18Mo steel originating from the mushy zone can be transported to the undercooled zone at the solidification front by TE magnetic convection (Fig. 10).

To illustrate how the structure evolves to form the final grain structure shown in Figs. 2, 3, 4, 5, the schematic illustrations of the grain structure at different growth stages without and with the axial static magnetic field are shown in Fig. 11. As shown in Fig. 11, the columnar dendrites grow steadily and then finally form columnar grains without the axial static magnetic field. When the axial static magnetic field is applied, the fragments detach from the primary dendrites. Then the TE magnetic convection transports the fragments from the interdendritic spacing to the region ahead of the solidification front. As solidification progresses, these grain fragments grow up ahead of the columnar dendrite tips. The advancing columnar solidification front will be blocked as soon as the concentration of the equiaxed crystals reaches a critical value. In this situation, most of the fragments tend to form new equiaxed grains. 


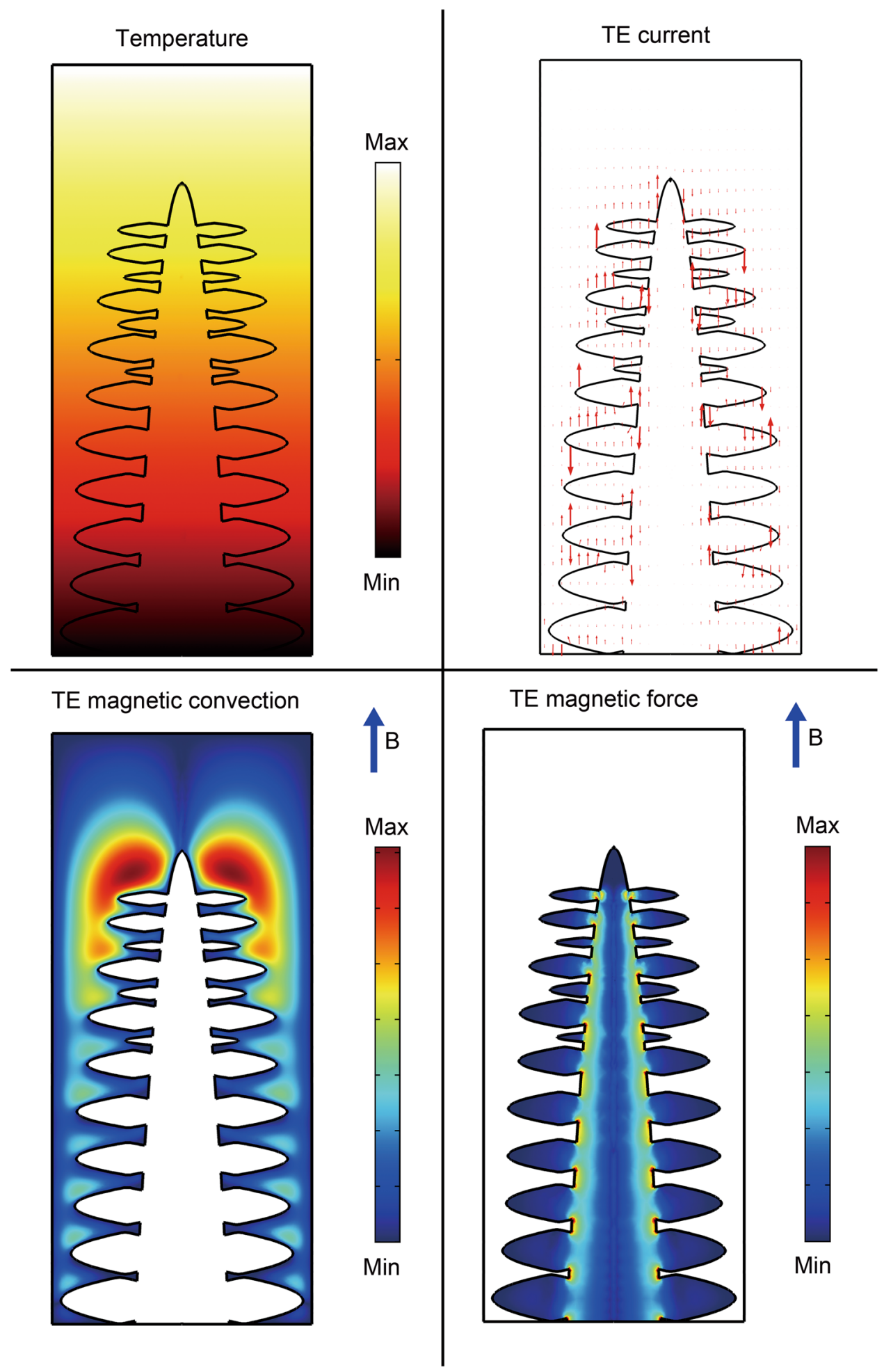

Fig. 10 Schematics for TE magnetic effects during directional solidification of alloys under an axial static magnetic field 


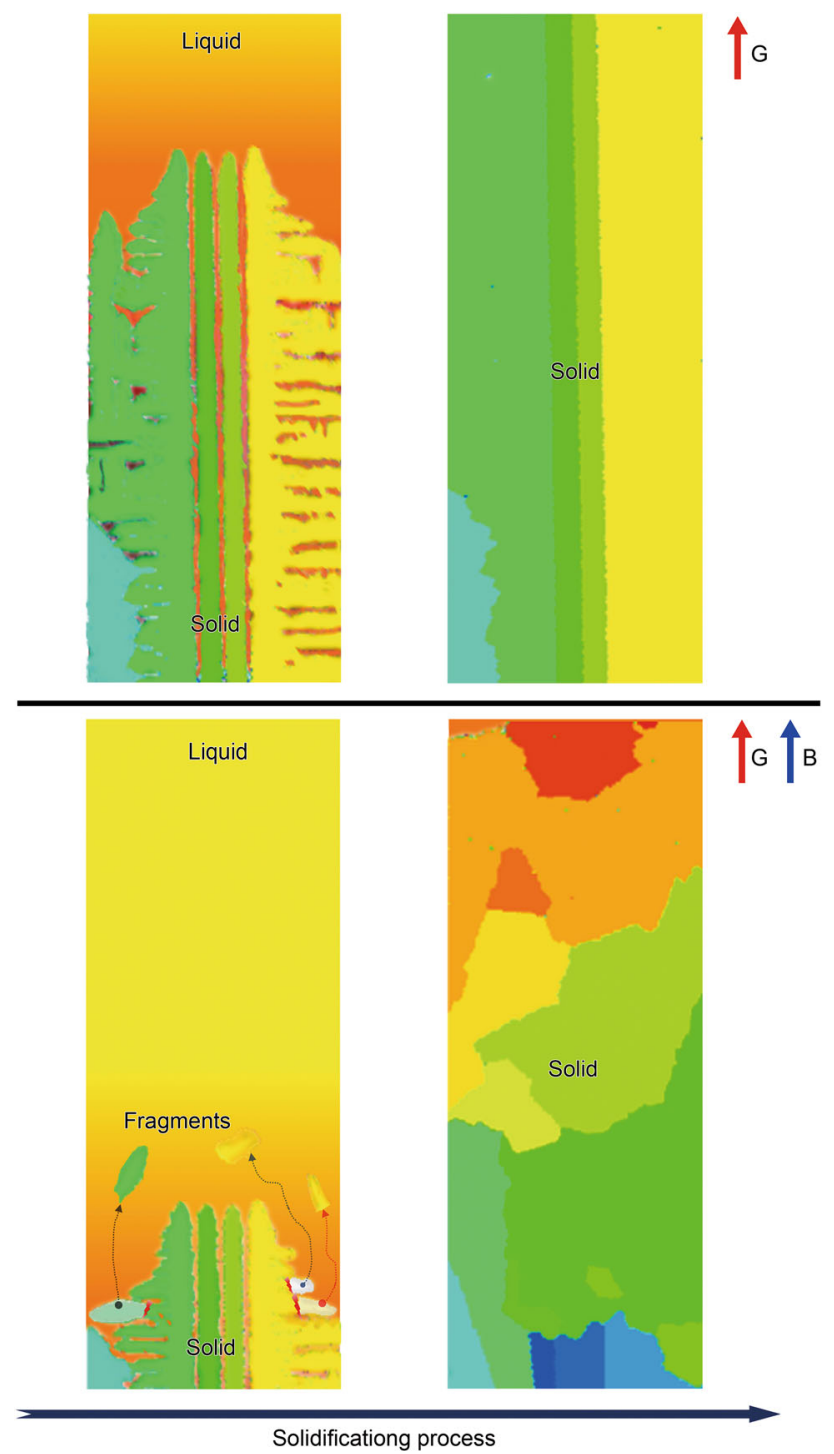

Fig. 11 Schematic illustration of grain refinement in GCr18Mo steel during directional solidification without and with axial static magnetic field

\section{Conclusions}

We investigated the effect of the axial static magnetic field on the directional solidification structures of GCr18Mo steel experimentally, and the results obtained are summarized as follows:

1. A pronounced decrease in grain size can be achieved with increasing intensity of magnetic field and temperature gradient in the directionally solidifying GCr18Mo steel. As a result, an equiaxed grain structure appears at lower growth speeds. Such an equiaxed grain structure is normally anticipated for much higher growth speeds owing to the classical CET.
2. The magnetic field can improve the uniformity of composition distribution in the directionally solidifying GCr18Mo steel. This result can explain the influence of the axial static magnetic field on the grain refinement of GCr18Mo steel in another way.

3. The above results may be caused by the TE magnetic convection in the melt and the TE magnetic force acting on the dendrite during directional solidification under the magnetic field.

This work demonstrates a potential approach to obtain grain refinement for the steel by applying an axial static magnetic field through a generated forced TE magnetic convection and TE magnetic force imposed on the dendrite.

Acknowledgements This work was financially supported by the Joint Funds of the National Natural Science Foundation of China (No. U1560202), the National Natural Science Foundation of China (Nos. 51604171 and 51690162), the Shanghai Municipal Science and Technology Commission Grant (No. 17JC1400602) and the United Innovation Program of Shanghai Commercial Aircraft Engine (Nos. AR910 and AR911).

\section{References}

[1] H.K.D.H. Bhadeshia, Prog. Mater. Sci. 57, 268 (2012)

[2] Z. Dong, B. Jiang, Z. Mei, C. Zhang, L. Zhou, Y. Liu, Steel Res. Int. 87, 745 (2016)

[3] R.A. Grange, ASM Trans. 59, 1 (1966)

[4] H. Qiu, L. Wang, T. Hanamura, S. Torizuka, ISIJ Int. 53, 382 (2013)

[5] P.F.F. Walker, A. Kerrigan, M. Green, N. Cardinal, J. Connell, Bear. Steel Technol. 10, 54 (2015)

[6] O. Grong, L. Kolbeinsen, V.D.E. Casper, G. Tranell, ISIJ Int. 46, 824 (2006)

[7] M. Kiviö, L. Holappa, T. Iung, Metall. Mater. Trans. B 41, 1194 (2010)

[8] M. Sasaki, K. Ohsasa, M. Kudoh, K. Matsuura, ISIJ Int. 48, 340 (2008)

[9] T. Watanabe, M. Shiroki, A. Yanagisawa, T. Sasaki, J. Mater. Process. Technol. 210, 1646 (2010)

[10] J.Z. Lu, K.Y. Luo, Y.K. Zhang, G.F. Sun, Y.Y. Gu, J.Z. Zhou, X.D. Ren, X.C. Zhang, L.F. Zhang, K.M. Chen, C.Y. Cui, Y.F. Jiang, A.X. Feng, L. Zhang, Acta Mater. 58, 5354 (2010)

[11] B. Abbasi-Khazaei, S. Ghaderi, J. Mater. Sci. Technol. 28, 946 (2012)

[12] T. Campanella, C. Charbon, M. Rappaz, Scr. Mater. 49, 1029 (2003)

[13] Q. Li, C. Song, H. Li, Q. Zhai, Mater. Sci. Eng. A 466, 101 (2007)

[14] K.H. Spitzer, M. Dubke, K. Schwerdtfeger, Metall. Mater. Trans. B 17, 119 (1986)

[15] A. Noeppel, A. Ciobanas, X.D. Wang, K. Zaidat, N. Mangelinck, O. Budenkova, A. Weiss, G. Zimmermann, Y. Fautrelle, Metall. Mater. Trans. B 41, 193 (2010)

[16] F.C. Robles Hernández, J.H. Sokolowski, J. Alloys Compd. 426, 205 (2006)

[17] S. Nafisi, D. Emadi, M.T. Shehata, R. Ghomashchi, Mater. Sci. Eng. A 432, 71 (2006) 
[18] D. Lu, Y. Jiang, G. Guan, R. Zhou, Z. Li, R. Zhou, J. Mater. Process. Technol. 189, 13 (2007)

[19] Z. Chen, X. Wen, C. Chen, J. Alloys Compd. 491, 395 (2010)

[20] T. Campanella, C. Charbon, M. Rappaz, Metall. Mater. Trans. A 35, 3201 (2004)

[21] H. Harada, T. Toh, T. Ishii, K. Kaneko, E. Takeuchi, ISIJ Int. 41, $1236(2001)$

[22] J.A. Shercliff, J. Fluid Mech. 91, 231 (2006)

[23] X. Li, A. Gagnoud, Z. Ren, Y. Fautrelle, R. Moreau, Acta Mater. 57, 2180 (2009)

[24] P. Lehmann, R. Moreau, D. Camel, R. Bolcato, Acta Mater. 46, 4067 (1998)

[25] P. Dold, F.R. Szofran, K.W. Benz, J. Cryst. Growth 291, 1 (2006)

[26] X. Li, A. Gagnoud, Y. Fautrelle, Z. Ren, R. Moreau, Y. Zhang, C. Esling, Acta Mater. 60, 3321 (2012)

[27] G. Zimmermann, C. Pickmann, M. Hamacher, E. SchabergerZimmermann, H. Neumann-Heyme, K. Eckert, S. Eckert, Acta Mater. 126, 236 (2017)

[28] D. Ruvalcaba, R.H. Mathiesen, D.G. Eskin, L. Arnberg, L. Katgerman, Acta Mater. 55, 4287 (2007)
[29] M.C. Flemings, Metall. Trans. B 22, 269 (1991)

[30] J. Yu, D. Du, Z. Ren, Y. Fautrelle, R. Moreau, X. Li, ISIJ Int. 57, 337 (2017)

[31] X. Li, Z. Ren, Y. Shen, Y. Fautrelle, Philos. Mag. Lett. 92, 675 (2012)

[32] X. Li, Y. Fautrelle, K. Zaidat, A. Gagnoud, Z. Ren, R. Moreau, Y. Zhang, C. Esling, J. Cryst. Growth 312, 267 (2010)

[33] T. Kato, H. Jones, D.H. Kirkwood, Mater. Sci. Technol. 19, 1070 (2003)

[34] F. Baltaretu, J. Wang, S. Letout, Z.M. Ren, X. Li, O. Budenkova, Y. Fautrelle, Magnetohydrodynamics 51, 45 (2015)

[35] W. Wang, S. Luo, M. Zhu, Comput. Mater. Sci. 95, 136 (2014)

[36] S. Taniguchi, J.K. Brimacombe, ISIJ Int. 34, 722 (1994)

[37] J.E. Enderby, B.C. Dupree, Philos. Mag. 35, 791 (1977)

[38] X. Li, Y. Fautrelle, Z. Ren, Acta Mater. 55, 3803 (2007)

[39] B. Cai, J. Wang, A. Kao, K. Pericleous, A.B. Phillion, R.C. Atwood, P.D. Lee, Acta Mater. 117, 160 (2016)

[40] A. Hellawell, S. Liu, S.Z. Lu, JOM 49, 18 (1997)

[41] J.D. Hunt, Mater. Sci. Eng. 65, 75 (1984) 